\title{
Recycled aggregates (RAs) for asphalt materials
}

\author{
B. Gomez-Meijide and I. Pérez, Universidade da Coruña, Spain
}

\begin{abstract}
In this chapter, we gather the results of the most innovative studies about recycled aggregates (RA) from construction and demolition waste (CDW), in an attempt to better understand the physical and mechanical performance of these materials, which are more economical, sustainable and environmentally friendlier, as an integral part of bituminous mixtures.
\end{abstract}

Key words: construction and demolition waste (CDW), recycled aggregates (RA), asphalt mixtures properties.

\section{Introduction}

Around the fifth millennium $\mathrm{BC}$ (in the late Neolithic period), one of the most important technological advances in history occurred: the wheel. Although it is widely believed that Mesopotamians initially conceived it as a potter's wheel, its use in transportation developed rapidly, as the need to supply food to the cities of these first civilizations grew and trading developed. Increased transport traffic between cities led to the need to build infrastructure. The engineering and construction of tracks and roads began.

Since then, during the past 7000 years, different civilizations have contributed to the development of roads and pavement, as they are known today. These developments included the solid Roman stone carriageways and the sophisticated road network of the Islamic Empire, which was already built with asphalt back in 700 BC; as well as the first modern British road systems of the 18th and 19th centuries, which led to the first toll roads, or the acclaimed German 'Autobahn' from the 1930s, precursor of modern freeways and high-performance roads of our times. Looking back into the past, it can be observed that, over and over again, different people have tried to build more solid and durable roads by more efficient and economical means. With the growing concerns about climate change, a new factor has recently become unavoidable: sustainability.

One means of achieving more sustainable pavements followed by current engineers is in the substitution of natural aggregates (NA) for recycled aggregates (RA), obtained, for example, from the construction and demolition of former buildings and infrastructures. Using materials which might otherwise be disposed of in garbage dumps and reducing the need to open new quarries, will help to ensure more sustainable pavements and combat global warming. Unfortunately, construction and demolition waste (CDW) from concrete structures can be contaminated with materials such as brick, gypsum, glass, bitumen, wood and rubber, among others (Ravindrarajah, 1996; Dumitru et al., 1996; Sagoe-Crentsil et al., 1996; Shayan et al., 1997; Arm, 2001; Gómez-Soberón, 2002; Chen et al., 2011a; Zaharieva et al., 2003). Therefore, results drawn from research focused on their use have led to scattered, unstable and sometimes contradictory conclusions.

Little research has been conducted concerning the mechanical performance, durability and economic impact of these new materials and, what is even more important, concerning their performance with regard to road safety. For these reasons, their application within bituminous mixtures constitutes one of the most important leading lines of investigation in highway engineering, although their use is still one step behind the application to other construction materials such as concrete.

This chapter aims to present the latest findings on the physico-mechanical performance of bituminous mixtures containing this type of aggregates, as well as outlining predictions about the effects of their multiple applications. As may be observed, many steps have already been taken and many satisfactory results have been obtained. However, this is just the starting point and, perhaps, as in the case of previous societies, the beginning of a 
new era. It cannot be denied that there is still a long way to go.

\section{Volumetric properties}

A sample prepared in the laboratory can be analysed to determine its probable performance inside the structure of a given pavement. Basic preliminary analysis, aimed at simply characterizing the materials in order to measure the mixtures afterwards, are mainly based on characteristics such as the specific gravity, amount of air voids, voids in the aggregates (filled either with air or bitumen) and absorption. The addition of RA to bituminous mixtures especially has an impact on two of them: the specific gravity and the absorption.

\subsection{Air voids}

Voids are the spaces inside a bituminous mixture that, once it has been manufactured and compacted, are not occupied by any aggregate and may be filled with air or bitumen. In general terms, RA from CDW are more porous than NA and they also show a high rate of binder absorption into the grains, thus leading to reductions in the thickness of the film that coats the aggregate. Thus, when they are added to bituminous mixtures, the volume of voids filled with air (Percent Voids Total Mix - VTM) increases, whereas the volume of voids filled with asphalt (Voids Filled with Asphalt - VFA) and of spaces between the aggregate particles (Voids in the Mineral Aggregate - VMA) tend to decrease (Paranavithana and Mohajerani, 2006; Pérez et al., 2010a; Shen and Du, 2005; Wong et al., 2007).

\subsection{Specific gravity}

The specific gravity of a compacted mixture is the ratio between the weight and a given specific volume. Low values are generally associated with low-quality aggregates, what may lead to poor performance once they have been added to a given pavement. Nevertheless, the addition of recycled materials to bituminous mixtures also leads, as a general rule, to slightly lower specific gravities when compared with those mixtures formed solely by NA. According to Poon and Chan (2006), NA show slightly higher specific gravities than recycled concrete aggregates and these, in turn, show higher specific gravities than those of clay-based aggregates.

Gómez-Soberón (2002) established that the specific gravity of RA is between 9 and 14\% lower than that of reference NA. Li (2004) also gave evidence of the great importance of the mortar adhered to recycled concrete aggregates, since the author considers that it may be the cause of many differences in performance between NA and RA. For example, the bulk dry specific gravities of the RA were found to be between 1.290 and 1.470, and the bulk Saturated Surface Dry Basis (SSD) specific gravities were between 2.310 and 2.620; placing them in between the typical densities of a natural rock aggregate and a lightweight aggregate. Moreover, there are many additional publications, such as Huang et al. (2002), Paranavithana and Mohajerani (2006), Pérez et al. (2007), Melbouci (2009), Mills-Beale and You (2010) and Gokce et al. (2011), that agree with the abovementioned trend.

\subsection{Absorption rate}

RA tend to be, as well as lightweight, very porous and absorbent, basically due to the presence of a high content of materials such as cement mortar, brick and, sometimes, wood particles. If a regular absorption rate is normally lower than $1.5 \%$ for natural quarry aggregates, some authors, such as those mentioned above, found values of 10.3 and $30.9 \%$ for fine concrete and clay-based aggregates, respectively (Poon and Chan, 2006); between 4 and $9.5 \%$ (Li, 2004); up to 8.8\% (Shen and Du, 2005); and 8.16\% (GómezSoberón, 2002), etc. This phenomenon must be taken into serious consideration when working with mixtures that require the addition of great amounts of water or, rather, with those requiring a precise water dosage, as is the case in cold bituminous mixtures made 
with asphalt emulsions.

\section{Rutting}

The rutting phenomenon may be motivated by a low shear strength of the bituminous mixtures used on the surfaces of flexible pavements; although the resistance to permanent deformations (PD) is also commonly attributed to the content of binder, the degree of compaction and to factors associated with the aggregates such as angularity, particle size distribution, grain-shape and roughness. However, in some cases, the substitution of NA for RA produces almost unpredictable effects and so a very controlled application is required. This is the case of RA from CDW, which contain fractions of concrete, brick, plaster, glass, bitumen, rubber and other materials. According to the wheel tracking tests carried out by Shen and Du (2005), hot mixtures containing 50\% of NA and $50 \%$ of RA showed a minimum PD, compared with all the results obtained from other mixtures containing different proportions or even $100 \%$ of NA, when conducted at $25{ }^{\circ} \mathrm{C}$; but a maximum PD when tested at $60{ }^{\circ} \mathrm{C}$. Therefore, they reported and classified such aggregate substitutions as unsuitable.

Pérez et al. (2012), after having conducted the same experiment on hot asphalt mixtures with RA substitution rates of $0,20,40$ and $60 \%$ containing cement or limestone fillers, concluded that all of them showed a good performance regarding PD, since in the 8 cases studied, the PD-rate (average deformation velocity of 3 specimens at the interval between 105 and 120 min from the start in a deformation vs. time graph) was lower than the maximum established by the Spanish standard PG-3 (Direccion General de Carreteras (2004). However, other research has shown adverse effects, such as the study conducted by Mills-Beale and You (2010), who, when using an asphalt pavement analyser at a temperature of $52{ }^{\circ} \mathrm{C}$, concluded that, for each number of load cycles, as the content of recycled concrete in the mixture increases, the PD also increases (Fig. 1).

However, other studies have concluded that mixtures containing coarse aggregates from CDW showed a similar performance to control mixes containing exclusively NA (Paranavithana and Mohajerani, 2006); which could be considered as a favourable result. This trend has been reaffirmed by Wong et al. (2007), substituting the fines and the natural filler for recycled concrete in small proportions (6\% of the total). They have proved that the results (in accordance with the Australian standard AS 2891.12.1, 1995) were considerably better in the case of greater substitutions (up to 45\%), since the number of load cycles had to be increased by up to 2 to 3 times to achieve the same deformation. However, it has also been found that greater porosity and high absorption substitution materials, such as the brick powder used as filler, provide the mixtures with better performance at high temperatures and lower PD (Chen et al., 2011a). In this study, both static and dynamic tests were conducted at $60{ }^{\circ} \mathrm{C}$ and, in all these tests, the deformations of mixtures containing brick powder were significantly lower than those shown by control mixes (containing 100\% of limestone) (Fig. 2).

Finally, there is evidence of studies conducted on hot mixtures containing different substitution materials such as Silestone ${ }^{\circledR}$ decorative stone debris which, despite their grain-shape being less favourable than that of the NA used in control samples (flakiness index of $18 \%$ instead of $5 \%$ ), showed very similar results in wheel tracking tests (Rubio et al., 2011).

\section{Stiffness}

The stiffness of bituminous mixtures is a key factor to analyse and design flexible pavements, since it is directly related to the capacity of the material to distribute the loads and also serves as a synthetic indicator of the structural properties of the mixtures (Pasetto 
and Baldo, 2011). Thus, some authors define the resilient modulus (or stiffness modulus) as an estimate of the elastic modulus of the material, based on the measurement of the stress and strain experienced by a specimen of bituminous material under high frequency cyclic loads, similar to those experienced by pavements under heavy traffic. Tests aimed at estimating this modulus are normally conducted in accordance with the American standard ASTM D 4123-82 (1995) or its analogues from other countries, such as the Australian standard AS 2891.12.1. In Europe, there is a reference standard, EN 1269726 (2006) (Annex $\mathrm{C}$ ), on indirect tensile strength testing on cylindrical specimens.

However, when materials show visco-elastic behaviour (as is the case of bituminous mixtures) the peaks of stress and strain due to cyclic loads do not occur simultaneously. Therefore, there would not be much sense in calculating a modulus that simply associates a given stress with a given strain at a given point in time. For this reason, the dynamic modulus $\left(\mathrm{E}^{*}\right)$ is defined as the absolute value of the complex modulus calculated through the ratio of the maximum stress (stress peak) and the maximum axial strain (strain peak) for each sinusoidal stress cycle.

In hot asphalt mixtures, the substitution of NA for RA of different natures may produce various and, sometimes, even beneficial effects. For instance, it has been observed that mixtures containing brick powder filler show a higher modulus than mixtures containing NA at temperatures of 5 and $40{ }^{\circ} \mathrm{C}$; but this value is lower at 25 ${ }^{\circ} \mathrm{C}$. This factor may indicate a better fatigue performance than in other mixtures, since this type of failure normally appears at the latter temperature (Chen et al., 2011a).

Construction debris, which contains fractions of concrete, brick, plaster and other materials such as plastic and wood, may bring about almost unpredictable effects, as happened in the case of PD. For example, Shen and Du (2005) achieved the highest modulus for stiff binders, in accordance with the standard ASTM D 4123-1995, by substituting only the fraction of coarse aggregate and preserving the natural fines; whereas for less stiff binders, the highest modulus was achieved by substituting $50 \%$ of the aggregate (in all its fractions) when the test was conducted at $25{ }^{\circ} \mathrm{C}$. However, when the test was conducted at $40^{\circ} \mathrm{C}$, and with the same aggregate substitution rate, the lowest results were obtained. Surprisingly, the highest modulus at $40{ }^{\circ} \mathrm{C}$ was achieved with a $100 \%$ substitution rate (Fig. 3).

Despite the instability of these results, in general, the resilient modulus tends to decrease when this type of material is added to the mixture and as the bitumen content increases, which may be attributed to the use of a low strength mortar together with a relatively lower quality aggregate (Paranavithana and Mohajerani, 2006). Moreover, the stiffness modulus also tends to decrease as the temperature increases (Wong et al., 2007) although, in this case, the results obtained were completely comparable (and even higher) to those samples containing solely NA. However, the tests conducted by Mills-Beale and You (2010) agreed on a decrease of the resilient modulus as the test temperature increased, but they also showed an opposing trend, thus achieving a higher value as the aggregate substitution percentage decreased (Fig. 4)

With regard to the dynamic modulus $\left(\mathrm{E}^{*}\right)$, no publications have been found on how hot and cold asphalt mixtures are affected by the addition of recycled materials as a substitute for NA. Nevertheless, studies carried out by Pérez et al. (2010a) proved that RA from construction and demolition debris, containing $50 \%$ of natural and $50 \%$ of RA in all its fractions, positively affect hot mixtures, thus slightly increasing their dynamic modulus in the case of coarse mixtures (without fines) and even having a more pronounced effect on semi-dense mixtures. Similarly, Mills-Beale and You (2010) studied the dynamic modulus of mixtures containing different percentages of recycled concrete. However, Pérez et al., 2010b), who applied the Spanish standard NLT-350 (1990) (3-point-flexion 
test), in turn conducted the tests in accordance with the American standard AASHTO T 62-03 (2004) (4-point-flexion test) at 13.2, 21.3 and $39.2{ }^{\circ} \mathrm{C}$ and at stress frequencies of 25, 10.5, 1 and 0.1. Consequently, they drew master curves (Fig. 5) that showed an opposite trend to Pérez et al. (2010a); that is, the higher the content of recycled concrete added to the mixture, the lower its dynamic modulus.

From these master curves, some other important conclusions can be drawn. It can be observed that, at low frequencies (Fig. 5, left), all mixtures containing RA perform in the same way, regardless of content, always showing a lower dynamic modulus than that of the sample containing $100 \%$ of NA. This indicates that, at high temperatures, mixtures containing RA will not be as stiff as mixtures containing NA. Therefore, they will be more prone to develop PDs. However, at high frequencies (Fig. 5, right), it can be observed how the dynamic modulus decreases as the content of RA increases. This means that, at low temperatures, mixtures with a higher content of RA will not be so stiff; thus being less prone to cracking, making them perfectly suitable for cold climates.

\section{Fatigue}

Fatigue is defined as the reduction in the strength of a material when subjected to repeated loading, in comparison to the strength when subjected to an individual loading. Bituminous mixtures are devised to be affected mainly by these types of loads throughout their useful life. Therefore, it is crucial factor that should be taken into account, even at the early stages of their design, in order to avoid the appearance of frequent pathologies such as the well-known 'alligator cracking'. Thus, for more than half a century, a wide range of methods aimed at measuring and quantifying fatigue have been developed. Nowadays, the current versions of those first tests, such as the four-point bending test included in the American standard AASHTO T-321 (2003), are still being used. The EN 12697-24 (2007) standard regarding bituminous mixtures, Bituminous Mixtures - Test Methodsfor Hot Mix Asphalt. Part 24: Resistance to Fatigue, prevails in Europe.

Several authors, such as Kim et al. (1985), indicated that the fatigue performance of hot bituminous mixtures is closely linked to the fracture characteristics of the bitumen matrix. It has also been proved that, in general terms, the higher the stiffness modulus of a mixture, the better fatigue performance achieved (Pasetto and Baldo, 2011). At the same level of stress, an increase in the stiffness of the mixture will imply the development of fewer deformations and so the risk of the appearance of cracks will decrease. However, several factors, such as the substitution of the whole or part of the NA for other types of aggregate, may affect the aforementioned law. As a general rule, CDW tend to affect fatigue laws negatively (Pérez et al., 2010a), although the registered effect was more pronounced on mixtures containing a vast amount of fines (such as semi-dense mixtures) than on coarse mixtures, whose values did not differ from those corresponding to reference mixtures without RA.

Chen et al. (2011b) established that mixtures containing recycled fines showed a better fatigue performance than aggregates containing limestone fines in any of the deformations studied (between 400 and $700 \mu \varepsilon$ ) (Fig. 6). Specifically, the brick powder used in the mixtures as filler provides them with a higher fatigue life in comparison with control mixes without recycled filler; being 1.73 and 1.75 times higher for 500 and 600 $\mu \varepsilon$, respectively (Chen et al., 2011a).

\section{Stripping and durability}

Stripping is a phenomenon that reduces the adhesive bond between the binder and the aggregate or by a softening of the cohesive bonds within the asphalt binder itself, normally under the loads of traffic and with the presence of moisture content inside the mixture. It usually begins at the bottom of a sealed layer and progresses upward, thus turning stripping into a phenomenon not easily detectable until the damage caused becomes evident and 
harmful. For this reason, the potential sensitivity of the mixtures to the presence of water is studied in laboratories (CTRE, 2005).

There are numerous factors that enhance their appearance, such as the type and use of the bituminous mixture, the characteristics of the mixtures and the aggregates, environmental factors during and after their placing, the use or not of anti-stripping additives, etc. The aforementioned causes trigger one of the two types of rupture mechanisms that have been studied until now: the failure of the aggregate-binder adhesion (adhesion failure) and/or the cohesion failure among the particles of its own binder (cohesion failure). With regard to both mechanisms, the former is the most widely accepted and, in the past, it was regarded by many authors as the only mechanism that could cause stripping (Kennedy, 1982; Majidzadeh and Brovold, 1968; Tunnicliff and Root, 1982).

In order to find a way to measure the water susceptibility of bituminous mixtures, since the 1930, many authors have proposed several test methods (Terrel and Shute, 1989). According to Hicks (1991), the process that leads to the collapse of the pavement due to water is divided in two phases: during the first phase, the aforementioned failures related to adhesion and cohesion appear; during the second phase, the mechanical failure appears under traffic loads, as a logical continuation of the first stage. There are, for instance, tests focused on the first phase, such as visual inspections, which consist of immersing specimens in hot or ambient temperature water to observe, after a certain period of time, the amount of uncoated aggregate. Laboratory tests, based on the second phase, where generally specimens are subjected to conditions similar to the real ones, subsequently compare their parameters (resilient modulus, indirect tensile strength, etc.) with those corresponding to unconditioned specimens. Finally, there is a third generation of tests, such as loaded wheel tests which, although designed to determine other pathologies such as rutting, are very useful in analysing water susceptibility as well.

In recent years, the study of water susceptibility of hot bituminous mixtures containing RA has progressed in different directions. Similar to other parameters previously covered in this text, the huge heterogeneity of RA from CDW justifies the fact that several authors have found noticeably different results, although there is a general trend toward the deterioration in the resistance to stripping. According to Mills-Beale and You (2010), water susceptibility increases as the content of RA in the mixture increases. This trend can be clearly observed through an increase in the Tensile Strength Ratio (TSR) as the amount of recycled content decreases, although it is true that only those samples containing $75 \%$ or more of RA fall below the minimum level of $75 \%$.

This same trend was confirmed by Pérez et al. (2010a), who concluded that some of the mixtures examined, such as coarse mixtures containing $50 \%$ of recycled content, obtained Retained Strength Index (RSI) values of 50\%, well below the minimum of $75 \%$ established by the Spanish Standard PG-3 (Direccion General de Carreteras, 2004). In this research, it has also been pointed out that voids do not excessively grow when RA are added, thus proving that failure is not due to a higher water intake inside the mixture. Therefore, bad results may be attributed to the nature of the RA, which contains adhered mortar that would contribute to water retention inside the mixture, thus displacing the bitumen from the surface of the grains. Shen and Du (2005) concluded that the substitution of NA for aggregates from construction wastes decreased the TSR (determined by the conditioned Marshall stability divided by the control Marshall stability) when compared to those mixtures containing $100 \%$ NA. Nevertheless, in this case, drops were not so sharp, since a minimum result of $87.71 \%$ was obtained in mixtures containing $100 \%$ of RA. In mixtures where only coarse fractions were substituted, very small reductions occurred, approximately $1 \%$ in comparison with reference mixtures. 
Pérez et al. (2012), after examining hot mixtures with RA substitution rates of 0, 20, 40 and $60 \%$ containing cement or limestone filler, also concluded that generally these mixtures showed a poor stripping performance, since only in 2 out of the 8 studied cases, the minimum required by the Spanish standard PG-3 was surpassed (Direccion General de Carreteras, (2004). Moreover, Pérez et al. (2010b) also verified the existence of drops in the TSR when RA were added, which were attributed to the poor adhesion between the aforementioned aggregates and the binder. Paranavithana and Mohajerani (2006) determined that the stripping potential (up to 34\%) was significantly higher than the one allowed (10\%). Moreover, they also verified that mixtures containing recycled concrete showed a very different performance under dry and wet conditions, owing to the high absorption of water and strippability of the mortar under mixing and compacting conditions.

Nevertheless, there are other materials that not only do not damage adhesiveness to bitumen, but also improve it. For example, Silestone ${ }^{\circledR}$ decorative stone debris shows a favourable performance of recycled fines (Rubio et al., 2011), or of electric arc furnace iron and steel slag, which develop less sensitivity to water than mixtures containing $100 \%$ of limestone aggregate and obtain a higher TSR as the amount of waste added to the mixture increases (Pasetto and Baldo, 2011).

Finally, some researchers, such as Chen et al. (2011a), have calculated the TSR index; although by subjecting mixtures containing recycled filler from brick powder to freezethaw cycles. Logically, the TSR decreases as the number of freeze-thaw cycles increases but, in general, it increases with the addition of recycled filler (Fig. 7).

\section{Conclusions}

Reusing CDW as aggregates of bituminous mixtures, instead of returning them to the environment through their disposal in garbage dumps while natural quarries are still being worked, implies a major advance in the field of highway engineering within the framework of the fight against climate change. Nevertheless, as described throughout this chapter, the aforementioned practice significantly influences their properties, both detrimentally and beneficially, even improving certain fundamental characteristics. Due to the great diversity and heterogeneity of the different types of RA, it is difficult to draw unique and universally applicable conclusions. However, it is indeed possible to observe certain general trends that affect the performance of bituminous mixtures after the addition of this type of aggregate. These trends are summarized below:

\subsection{Specific gravity andabsorption}

In general, the high porosity and lightness of the cement mortar adhered to the recycled concrete aggregate provides bituminous mixtures with slightly lower specific gravities (i.e. 9 and 14\%) and a significantly higher absorption (even reaching values up to 7 times higher). Other construction wastes, such as brick, enhance these effects, reaching lower specific gravities and absorptions above 30\% (as against customary values of NA, <1.5\%). This phenomenon should be taken into serious consideration when working with mixtures that require the addition of precise amounts of water, such as cold bituminous mixtures made with asphaltemulsions.

\section{2. $\quad$ Rutting}

In the light of various research, it still remains unclear whether the addition of aggregates from CDW is beneficial or detrimental. Both within cold and hot asphalt mixtures, beneficial and detrimental results were analysed, being difficult to predict when using different test temperatures and binder content. Particularly good results were obtained from the addition of brick powder to Silestone ${ }^{\circledR}$ decorative stone.

\subsection{Stiffness}

As in the previous case, both within the resilient and the dynamic modulus, it also remains 
unclear whether the addition of recycled materials has beneficial or detrimental effects on bituminous mixtures, having found very unstable and contradictory results.

\subsection{Fatigue}

Despite the fact that resistance to fatigue is normally related to the stiffness of bituminous mixtures, more positive results than negative results have been found, particularly through the substitution of natural filler for recycled filler. For example, the brick powder used in the mixtures as filler provides them with a higher fatigue life compared with control mixes without recycled filler, being 1.73 and 1.75 times higher for 500 and $600 \mu \varepsilon$, respectively.

\subsection{Stripping}

It can be concluded that, in general terms, resistance to stripping decreases or is negatively affected when the amount of aggregate from CDW increases. In some cases, the resistance to the action of water was held above $75 \%$ (the usually required minimum value), although in other cases this resistance decreased to $50 \%$. These reductions may be explained by the nature of RA containing adhered mortar, which prevents water from coming out from the interior of the mixture, thus displacing the bitumen from the surface of the grains. Nevertheless, it has also been found that other materials, such as Silestone ${ }^{\circledR}$ decorative stone debris, brick powder or granulated blast furnace slags, significantly increase the TSR index, thus improving the performance of bituminous mixtures.

\subsection{Summary}

Few solid conclusions can be drawn, so it is recommended that a particular study be conducted for each case, thus verifying whether the available RA is able to yield positive results. Nevertheless, positive experiences clearly indicate that, under certain requirements, it could be possible to make bituminous mixtures using RA, which are as good as or even better than those mixtures that only contain NA. So all the research reported throughout this chapter is just the starting point of a way that, without doubt, will be developed over the next few years to make road engineering more sustainable and economical.

\section{Acknowledgments}

The authors wish to acknowledge the Spanish Ministry of Education and Science for sponsoring this research through Project BIA2010-17751, as well as the authors who have generously allowed us to use the graphs shown throughout this chapter, and the publisher, Woodhead Publishing, for giving us the opportunity to participate in this fascinating project.

\section{References}

- AASHTO T 62-03 (2004), Determining Dynamic Modulus of Hot-Mix Asphalt Concrete Mixtures, Washington, DC, American Association of State Highway and Transportation Officials (AASHTO).

- AASHTO T321 (2003), Standard Method of Test for Determining the Fatigue Life of Compacted Hot-Mix Asphalt (HMA) Subjected to Repeated Flexural Bending,

- Washington, DC, American Association of State Highway and Transportation Officials (AASHTO).

- Arm M (2001), 'Self-cementing properties of crushed demolished concrete in unbound layers: Results from triaxial tests and field tests' Waste Management, 21, 235-239.

- AS 2891.12.1-1995 (1995), 'Methods of sampling and testing asphalt Determination of the permanent compressive strain characteristics of asphalt Dynamic creep test', Australian Standards.

- ASTM D4123-82 (1995), Standard Test Method for Indirect Tension Test for Resilient Modulus of Bituminous Mixtures, West Conshohocken, PA, American Society for Testing and Materials. 
- CTRE (2005), Evaluation of hot mix asphalt moisture sensitivity using the Nottingham asphalt test equipment, Final Report, lowa State University.

- Chen M Z, Lin J T and Wu S P (2011a), 'Potential of recycled fine aggregates powder as filler in asphalt mixture', Construction and Building Materials, 25, 3909-3914.

- $\quad$ Chen M Z, Lin J T, Wu S P and Liu C H (2011b), 'Utilization of recycled brick powder as alternative filler in asphalt mixture', Construction and Building Materials, 25, 1532 1536.

- Dirección General de Carreteras (2004), 'Pliego de prescripciones técnicas generales para obras de carreteras y puentes PG-3, Orden Ministerial FOM/891/2004', Directorate general of highways. General technical specifications for highway and bridge construction PG-3, Madrid (in English).

- Dumitru I, Formosa M and Zdrilic A (1996), 'Manufacture of base material using recycled concrete to comply with RTA(NSW) specifications', Programme and Proceedings of the Use of Recycled Materials in Engineering Construction, 7, 211.

- EN 12697-24 (2007), 'Bituminous mixtures - Test methods for hot mix asphalt. Part 24: Resistance to fatigue', Brussels, European Committee for Standardization.

- EN 12697-26: (E) Annex-C (2006), 'Test methods for hot mix asphalt. Stiffness', Brussels, European Committee for Standardization.

- Gokce A, Nagataki S, Saeki T and Hisada M. (2011), 'Identification of frostsusceptible recycled concrete aggregates for durability of concrete', Construction and Building Materials, 25, 2426-2431

- Gómez-Soberón J M V (2002), 'Porosity of recycled concrete with substitution of recycled concrete aggregate. An experimental study', Cement and Concrete Research, 32, 1301-1311.

- Hicks R G (1991), Moisture Damage in Asphalt Concrete, Washington, DC, Transportation Research Board, 175.

- Huang W L, Lin D H, Chang N B and Lin K S, (2002), 'Recycling of construction and demolition waste via a mechanical sorting process', Resources, Conservation and Recycling, 37, 23-37.

- Kennedy T W, Roberts F L and Lee K W (1982), 'Evaluation of moisture susceptibility of asphalt mixtures using the Texas freeze-thaw pedestal test,' Proceedings of the Association of Asphalt Paving Technologists, 53.

- Kim Ok-Kee, Bell C A and Hicks R G (1985), 'The effect of moisture on the performance of asphalt mixtures', ASTM STP, 899, 51-72.

- Li J (2004), 'Study on mechanical behavior of recycled aggregate concrete', MSc thesis, Tongji University, Shanghai.

- Majidzadeh K and Brovold F N (1968), 'Effect of water on bitumen - aggregate mixtures

- State of the art', Special HRB Report, 98.

- Melbouci B (2009), 'Compaction and shearing behavior study of recycled aggregates,'

- Construction and Building Materials, 23, 2723-2730.

- Mills-Beale J and You Z (2010), 'The mechanical properties of asphalt mixtures with recycled concrete aggregates', Construction and Building Materials, 24, 230-235.

- NLT-350 (1990), 'Ensayo de fatiga en flexotracción dinámica de mezclas bituminosas', Madrid, Ministerio de Obras Públicas y Transportes.

- Paranavithana S and Mohajerani A (2006), 'Effects of recycled concrete aggregates on properties of asphalt concrete', Resources Conservation and Recycling, 48, 1-12.

- Pasetto M and Baldo N (2011), 'Mix design and performance analysis of asphalt concretes with electric arc furnace slag', Construction and Building Materials, 25, 3458-3468.

- Pérez I, Toledano M, Gallego J and Taibo J (2007), 'Mechanical properties of hot mix asphalt made with recycled aggregates from reclaimed construction and demolition debris', Materiales de Construcción, 57(285), 17-29.

- Pérez I, Gallego J, Toledano M, and Taibo J (2010a), 'Asphalt mixtures with construction and demolition debris', Proceedings of the Institution of Civil Engineers, 163, 165-174. Pérez I, Pasandín A R and Gallego J (2010b), 'Stripping in hot mix asphalt produced by aggregates from construction and demolition waste', Waste 
Management and Research,

- 30(1), 3-11.

- Pérez I, Pasandín A R and Medina L (2012), 'Hot mix asphalt using C\&D waste as coarse aggregates', Materials and Design, 36, 840-846.

- Poon C S and Chan D (2006), 'Feasible use of recycled concrete aggregates and crushed clay brick as unbound road sub-base', Construction and Building Materials, 20, 578-585.

- Ravindrarajah R S (1996), 'Effects of using recycled concrete aggregates on the engineering properties of concrete', Programme and Proceedings of the Use of Recycled Materials in Engineering Constructions; 147-152. Available from: http://trid.trb.org/view. aspx?id=476018

- Rubio M C, Menéndez A, Moreno F, Belmonte A and Ramírez A (2011), 'Mechanical properties of hot bituminous mixes manufactured with recycled aggregate of Silestone ${ }^{\circledR}$ waste', Materials and Construction, 61(301), 49-60.

- Sagoe-Crentsil K K, Brown T, Mak S L and Taylor A (1996), 'Engineering properties and performance of concrete made with recycled construction aggregates', Programme and Proceedings of the Use of Recycled Materials in Engineering Constructions; 132-135. Available from: http://trid.trb.org/view/1996/C/1204539

- Shayan A, Bell D and Westgate P (1997) 'Performance of recycled concrete as a road- making material,' Municipal Engineering in Australia, 26, 28-30.

- Shen D H and Du J C (2005), 'Application of gray relational analysis to evaluate HMA with reclaimed building materials', Journal of Materials in Civil Engineering, 17(4), 400-406.

- Terrel R L and Shute J W (1989), Summary Report on Water Sensitivity, Strategic Highway Research Program, Washington, DC, National Research Council.

- Tunnicliff D G and Root R E (1982), 'Anti-stripping additives in asphalt concrete State of the art 1981', Proceedings of the Association of Asphalt Paving Technologists, 53. Available from: http://trid.trb.org/view.aspx?id=725888

- Wong Y D, Sun D D and Lai D (2007), 'Value-added utilization of recycled concrete in hot-mix asphalt', Waste Management, 27, 294-301.

- Zaharieva R, Buyle-Bodin F, Skoczylas F and Wirquin E (2003), 'Assessment of the surface permeation properties of recycled aggregate concrete', Cement and Concrete Composites, 25, 223-32.

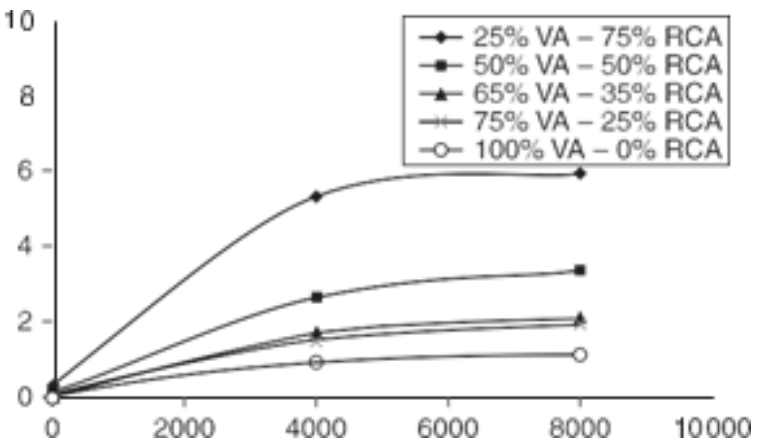

Figure 1. Permanent deformation for mixtures with different content of recycled concrete aggregate (RCA) and virgin aggregate (VA), ranging from $0 \%$ (line with circles) up to $75 \%$ (line with diamonds) (Mills-Beale and You., 2010). 

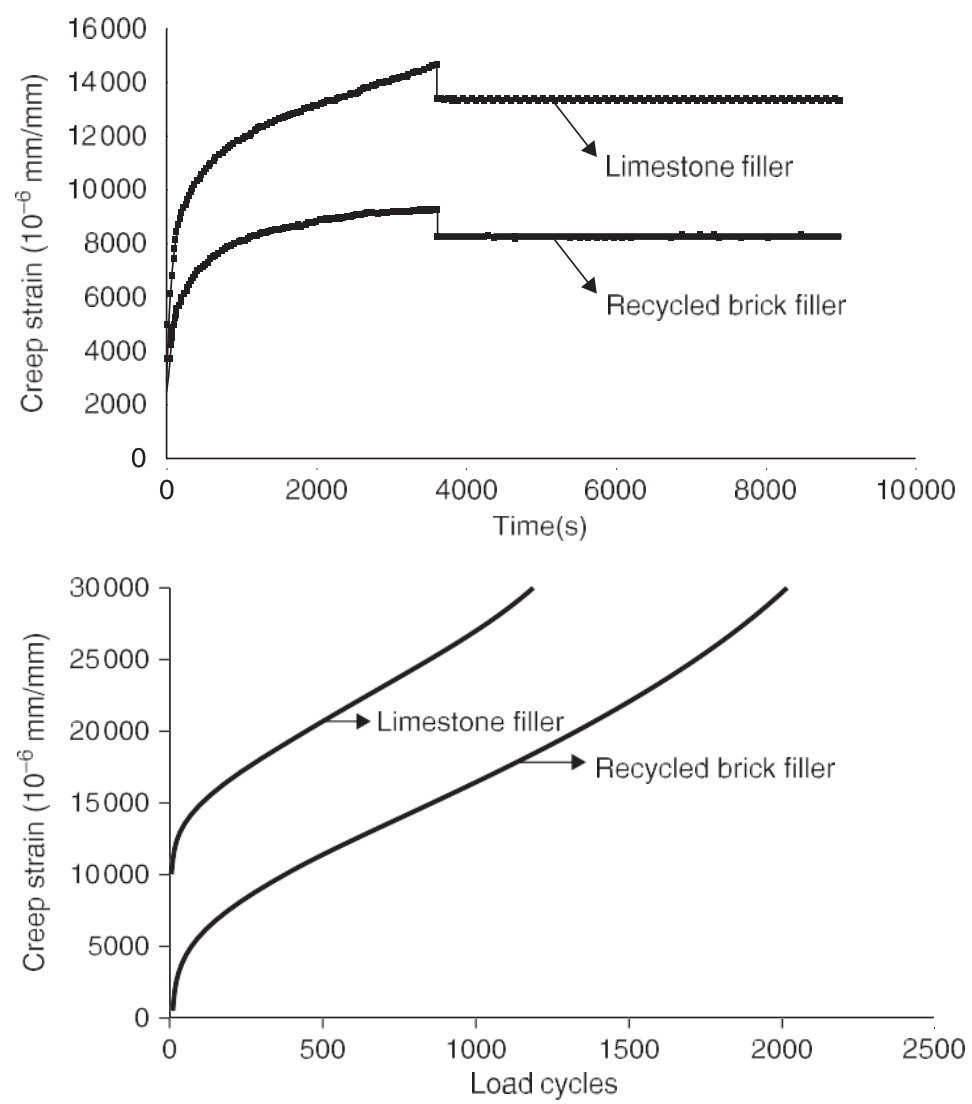

Figure 2. Static (upper) and dynamic (lower) creep strain of asphalt mixtures containing limestone filler and filler from brick powder (Chen et al., 2011a). 

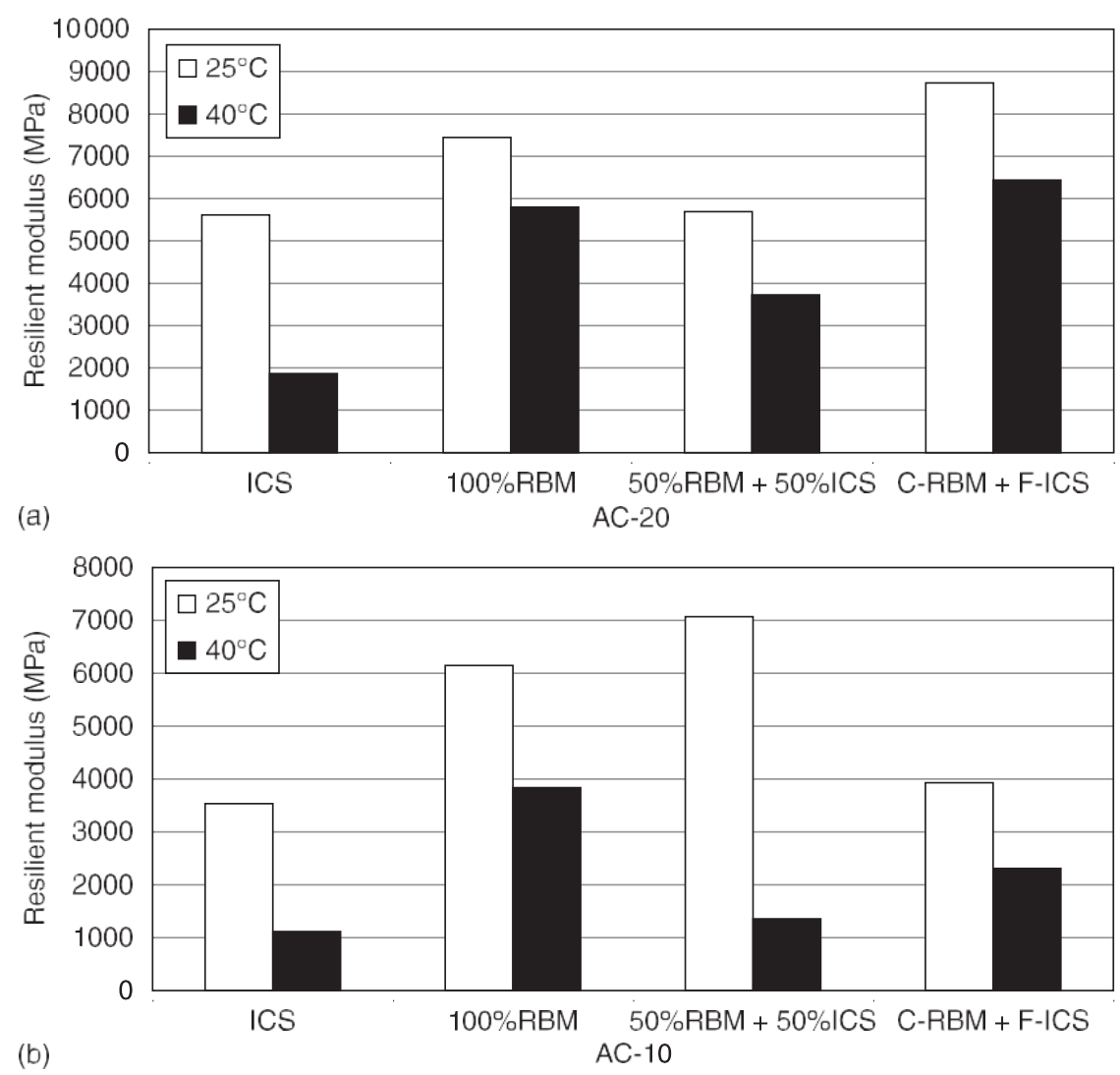

Figure 3. Resilient modulus at different temperatures and for different substitution percentages (0, 100 and $50 \%$ and containing recycled material only in the coarse fraction) using a Pen 60-70 bitumen AC-20 (a); and Pen 85-100 AC-10 (b) (Shen and Du, 2005, with permission from ASCE).

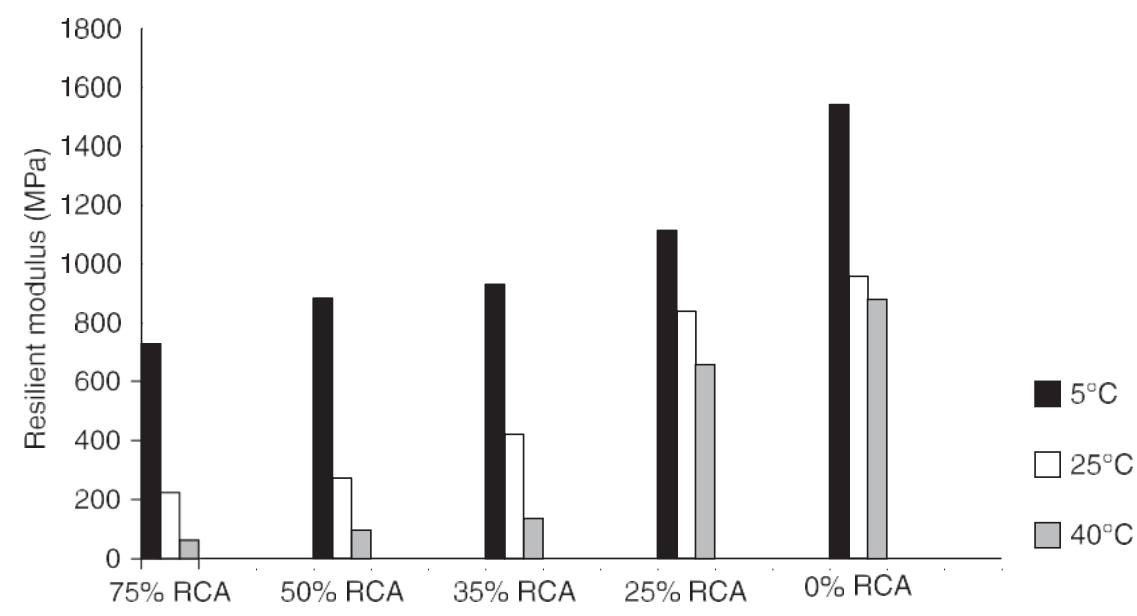

Figure 4. Resilient modulus test results (ASTM D 4123-82) at different temperatures and for different recycled aggregate percentages (Mills-Beale and You, 2010). 


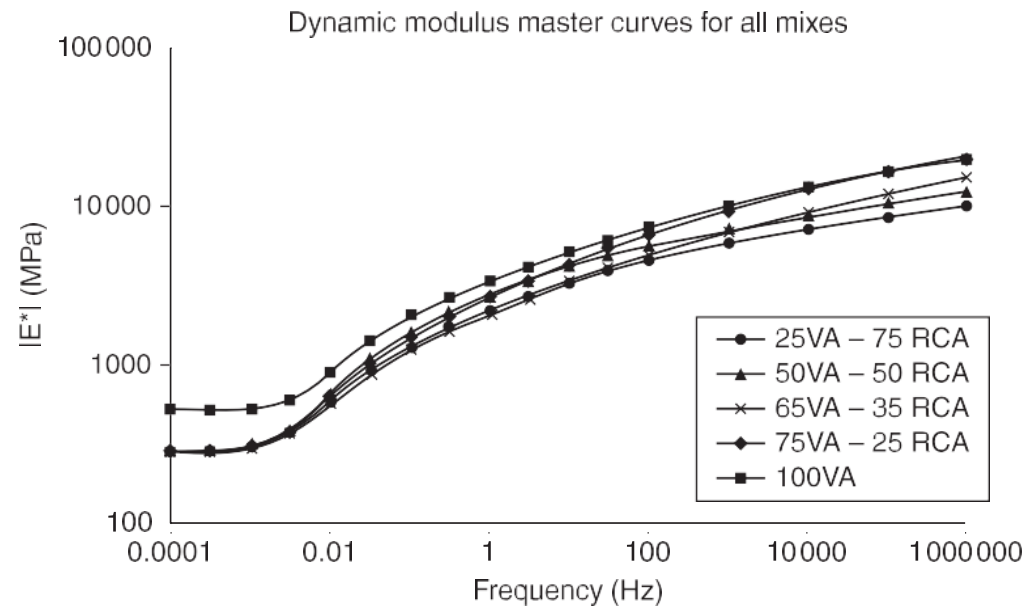

Figure 5. Dynamic modulus master curves for different contents of recycled concrete, ranging from $0 \%$ (line with squares) up to $75 \%$ (line with circles) (Mills-Beale and You., 2010).

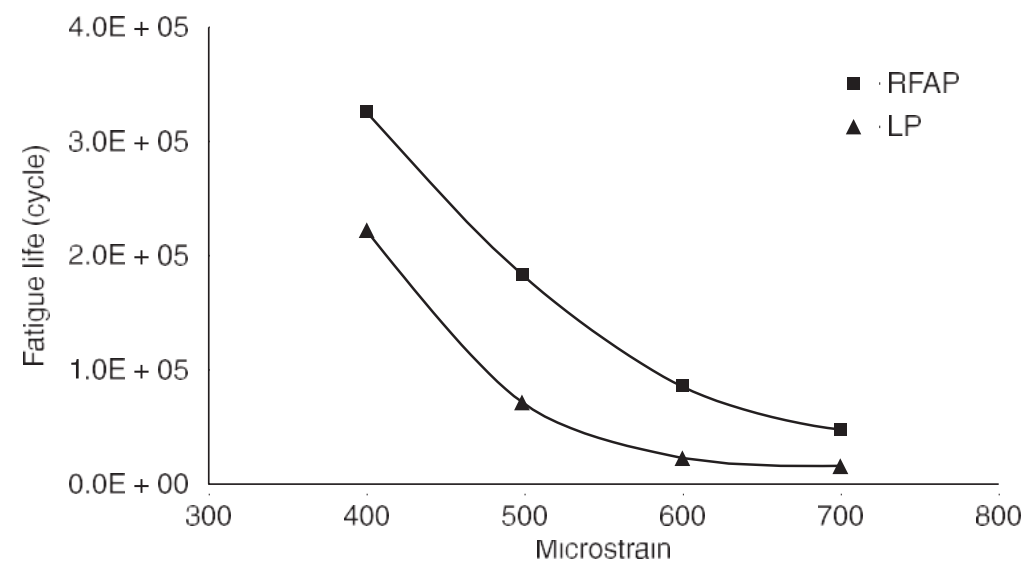

Figure 6. Cycle number to failure versus strain level of hot bituminous mixtures containing recycled fines (RFAP) or limestone aggregates (LP) (Chen et al., 2011b). 


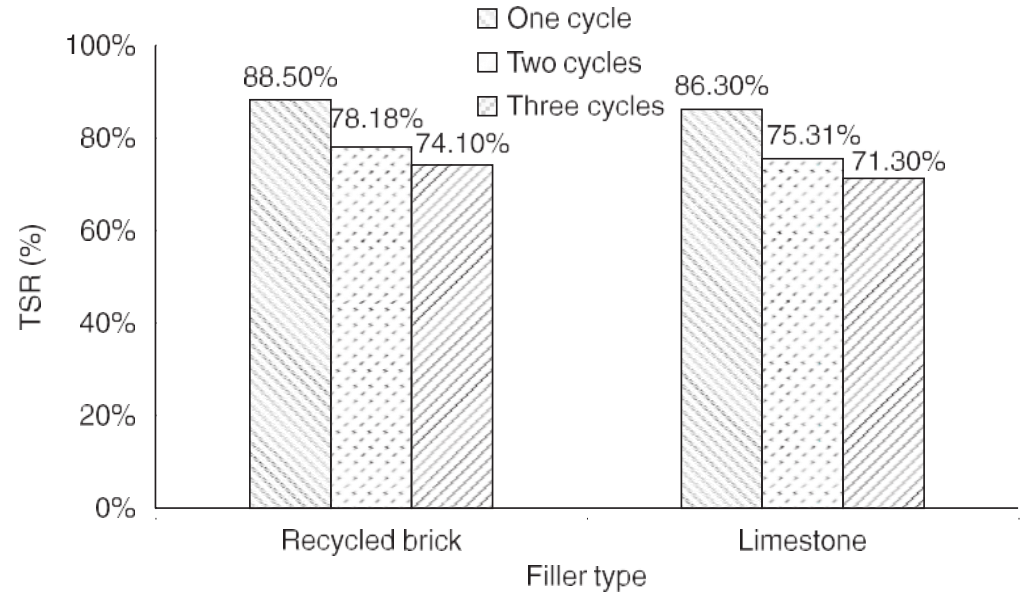

Figure 7. TSR values of asphalt mixtures with different filler (Chen et al., 2011a). 